\title{
Analytical Design of Multi-loop Fractional IMC-PID-Filter Controllers for MIMO System Using Equivalent NIOPDT Models
}

\author{
SAMI LAIFA \\ Advanced Control Laboratory \\ (LABCAV), \\ Department of Electronics and \\ Telecommunications, \\ Université 8 Mai 1945 Guelma \\ BP 401, Guelma 24000,
} ALGERIA

\author{
BADREDDINE BOUDJEHEM \\ Advanced Control Laboratory \\ (LABCAV), \\ Department of Electrotechnics \\ and Automatic, \\ Université 8 Mai 1945 Guelma \\ BP 401, Guelma 24000, \\ ALGERIA
}

\author{
DJALIL BOUDJEHEM \\ Advanced Control Laboratory \\ (LABCAV), \\ Department of Electronics and \\ Telecommunications, \\ Université 8 Mai 1945 Guelma \\ BP 401, Guelma 24000, \\ ALGERIA
}

\begin{abstract}
In this paper, a multiloop fractional IMC-PID-filter controller design is proposed for $2 \times 2$ multivariable systems (two-input two-output (TITO) system). The MIMO system is decomposed by an inverted decoupler into independent loops (SISO systems) and they are approximated to equivalent new fractional order models known as non integer order plus time delay (NIOPTD). The fractional property of the suggested controller is imposed by choosing the Bode's ideal closed loop transfer function as the reference model for each loop. The design method is based on the internal model control (IMC) paradigm. Finally, an illustrative example of MIMO process is provided and a comparative study is conducted out to demonstrate the advantages of the proposed method where the simulation results show the superior performance obtained by a multi-loop fractional IMC-PID-filter controllers in comparison with fractional PI/PID controllers based on simplified decoupling smith predictor (Fractional-SDSP and Classical-SDSP) structure as well as classical decentralized PID controllers using root locus method.
\end{abstract}

Key-Words: - Multi-loop fractional IMC-PID-filter controller; internal model control (IMC); MIMO System; NIOPTD model.

Received: May 2, 2020. Revised: August 20, 2020. Accepted: September 2, 2020. Published: September 17, 2020.

\section{Introduction}

The phenomenon of interactions between inputs and outputs of multivariate systems is one of the reasons leading to the difficulty of controlling them. Tuning the controller parameters of one loop can affect the performance of the others. To apply multiloop control successfully, There is a need to insert a device decoupler [1] between the process that must be controlled and the controller, So that the inputs and outputs are controlled independently, Most of industries are using the classical multiloop controller (decentralized PI/PID controller [2, 3, 4]) for its well-known advantage of easy implementation, robustness performance and flexibility. for example, Chananchai et al. [5] proposed the design of an inverted decoupler to weaken unwanted interference into TITO systems which allowed the Configuration of a high order sub-systems (SISO system), The each loop of SISO system was reduced as FOPDT model by frequency response fitting, As the decentralized PID controller parameters were designed using root locus technique. Jin, $\mathrm{Q}$ et al. [6] developed an IMC (internal model control ) based controller for TITO process, the complex model is decoupled into independent SISO system and then a Maclaurin series expansion technique is applied to reduced the SISO system. Then, the IMC based controller parameters are tuned for a reduced order model. Rajapandiyan C and Chidambaram M [7] have designed independent classical (PI/PID) controllers based on the new equivalent transfer function (ETF) model of the decoupled process by simplified decoupler matrix, and the parameters of multi-loop controllers are determined using the simplified internal model control (SIMC) method. 
Recently, the concept of fractional order controller which involves fractional derivative and integrals are more attractive became popular in industries and academia, it achieved promising results in its application to SISO systems $[8,9,10,11]$ compared to conventional PI/PID controllers known in the literature. Among the methods also, the fractional order (FO) was combined with the internal model control (FOIMC) to design the controller and to achieve the tuning parameters, as the simple scheme makes the FOIMC technique easy to be implemented. In [12], a new design Approach for a fractional FOPID controller based on internal model control (IMC) named a fractional IMC-PID controller is proposed to handle fractional order models with time delay. M. Bettayeb et al. [13] proposed a new approach of design fractional order PID controllers cascaded with a fractional filter is based on the internal model control (IMC) paradigm for fractional-order systems.

However, the design of fractional controllers was not limited to SISO systems only, but was expanded to include multivariate systems. Laifa and Boudjehem $[14,15]$ proposed a new design method for fractional PI controller of three-input-threeoutput $(3 \times 3)$ multivariable process using diffusive representation the controller parameters are optimally tuned by GA technique minimizing integral absolute error (IAE). Laifa and Boudjehem [16] introduced a new Analytical method to design a decentralized fractional order controllers based on gain and phase margin specifications (GPM) for a TITO system $(2 \times 2) \quad$ with simplified decoupler. Lakshmanaprabu, S.K., et al [17] developed an independent design of multi-loop fractional order internal model control (IMC) based PID (FOIMCPID) controller for TITO system is presented. The TITO system is decomposed by ideal decoupler to the SISO system and then it is converted into FOPDT model and controller parameters are optimally tuned independently using New Bat Optimization Algorithm (NBOA). Tassadit CHEKARI et al. [18] proposed the a new IMC-PID fractional order filter multi-loop controller design approach for MIMO processes with time delays Based on Two Degrees of Freedom Control (2DOF) structure. In [19], the fractional order internal model control (IMC) with inverted decoupling is proposed to handle fractional order TITO (FO-TITO-IMC) process with time delay. In [20], the fractional simplified decoupling Smith predictor structure (FSDSP) for two-input and two-output systems proposed by Chuong et al [21], is adopted to remove dead time out of the diagonal elements of the decoupled subsystem, The tuning rules of the fractional PI/PID controller are also derived by analytical method based on the internal model control (IMC) structure for the dead time -free parts of the reduced fractional models.

This paper discusses the design of a multi-loop fractional order controller for efficient control of the TITO system, This is done in two basic ideas. first, we remove the interaction between system variables by introducing an inverted decoupling between the controlled system and the controller, and from it is divided into decoupled sub-systems (independent SISO systems), also the each loop of the SISO system is reduced to equivalent fractional order models of type NIOPTD-I (One Non-integer Orders plus Time Delay). Second idea, the objective of the design is to control any open-loop system with closed-loop specifications Based on Bode's ideal transfer function, the internal model control (IMC) structure will be used for this purpose. The proposed multi-loop fractional IMC-PID-filter controllers design can be analytically derived for each fractional order model (NIOPTD-I).

Our contribution in this paper is organized as follows: A brief definition of the fractional order systems is presented in section 2. In Section 3. The inverted decoupler is designed for $(2 \times 2)$ MIMO system. With explaining how to convert independent SISO systems into equivalent NIOPTD-I models. The design of the multi-loop fractional IMC-PID-filter controller by the proposed methodology is discussed in Section 4. In section 5, good simulation is given to demonstrate efficiency and effectiveness the applicability of the proposed design technique to other FOPID design methods. Finally, Section 5 draws the main conclusions highlighted in the proposed work.

\section{Fractional-Order System (FOS) 2.1. Definition}

A fractional-order system (FOS) in the areas of dynamical systems and control theory, is defined as a dynamic system that can be modeled and expressed by a fractional differential equation that includes derivatives of non-integer order.[22] and can be defined as follows.

$H\left(D^{\alpha_{0} \alpha_{1} \alpha_{2} \ldots \alpha_{N}}\right)\left(y_{1}, y_{2}, \ldots \ldots y_{l}\right)=$
$G\left(D^{\beta_{0} \beta_{1} \beta_{2}, \ldots \beta_{M}}\right)\left(u_{1}, u_{2}, \ldots \ldots u_{k}\right)$

Where: $y_{i}, u_{i}$ are Functions of time.

$H, G$ : are Combinations of operators (D) of the fractional derivative. 
$D$, is fractional derivative operator $D$ of orders $a_{1}, a_{2} \ldots a_{n}$ and $\beta_{1}, \beta_{2} \ldots \beta_{m}$.

For SISO linear time-invariant (LTI) system equation (1) becomes: Eq. 21

$H\left(D^{\alpha_{0} \alpha_{1} \alpha_{2} \ldots \alpha_{N}}\right) y(t)=G\left(D^{\beta_{0} \beta_{1} \beta_{2}, \ldots . \beta_{M}}\right) u(t)$

is put :

$\left\{\begin{array}{l}H\left(D^{\alpha_{0} \alpha_{1} \alpha_{2} \ldots \alpha_{N}}\right)=\sum_{k=0}^{n} a_{k} D^{\alpha_{k}} \\ G\left(D^{\beta_{0} \beta_{1} \beta_{2}, \ldots . \beta_{M}}\right)=\sum_{k=0}^{m} b_{k} D^{\beta_{k}}\end{array}\right.$

With: $a_{k}, b_{k} \in \mathbb{R}$

Finally we obtain the fractional order differential equation:

$a_{n} D^{\alpha_{n}} y(t)+a_{n-1} D^{\alpha_{n-1}} y(t)+\cdots+a_{0} D^{\alpha_{0}} y(t)=$ $b_{m} D^{\beta_{m}} u(t)+a_{m-1} D^{\beta_{m-1}} u(t)+\cdots+$

$b_{0} D^{\beta_{0}} u(t)$

By applying the Laplace transform of LTI system equation (2) with the initial conditions zero, we obtain the following transfer function of the fractional system:

$$
G(p)=\frac{Y(s)}{U(s)}=\frac{\sum_{k=0}^{n} b_{k} s^{\beta_{k}}}{\sum_{k=0}^{m} a_{k} s^{a_{k}}}
$$

For $a_{k}$ and $\beta_{k}$ orders this is a non-standard transfer function.

\subsection{Bode's ideal transfer function}

Bode [23] proposed an ideal shape of the openloop transfer function of the type

$$
L(s)=\frac{1}{\tau_{c}{ }^{\alpha}} \quad \alpha \in \mathbb{R}
$$

Where:

$w_{c}$ is the gain crossover frequency.

The characteristics of open loop Bode's ideal transfer function curve are

The amplitude curve of the transfer function has a straight line with Constant slope of $-a 20 \mathrm{~dB} / \mathrm{dec}$.

The phase curve is a constant horizontal line at $-a(\pi / 2) \mathrm{rad}$.

We consider the closed loop transfer function $L(s)$ corresponding to the unity feedback system represented in Fig.1 is based on Bode's ideal transfer function $L(s)$ inserted in the forward path is:

$$
f(s)=\frac{L(s)}{1+L(s)}=\frac{1}{1+\tau_{c} s^{\alpha}}
$$

In this study, L(s) is the desired closed-loop and used as a reference model for tuning and design the controller $C(s)$.

Where the closed-loop transfer function of Fig. 1 is

$G_{c l}(s)=\frac{C(s) G(s)}{1+C(s) G(s)}$

For more details of important properties to closedloop based on Bode's ideal transfer function (see in $[13,24,25,26])$.

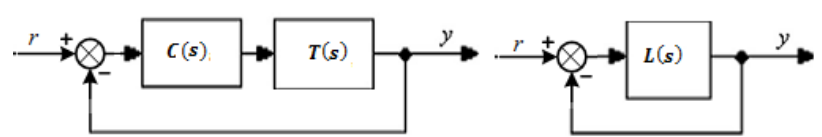

Fig. 1. Closed loop Bode's Ideal transfer function

\section{Inverted Decoupling design for TITO (two inputs, two outputs) Systems:}

The TITO (two-input two-output) model of this system is defined by the $G(s)$

$$
G(s)=\left[\begin{array}{ll}
G_{11}(s) & G_{12}(s) \\
G_{21}(s) & G_{22}(s)
\end{array}\right]
$$

For the success of the application of the multiloop control, a technique is required to assess the degree of interaction between the loops. The both Relative Gain Array (RGA) method and Niderlinksi Index (NI) offer important insights into the issue of control configuration selection. RGA method is used to measure interactions between input and output, while Niderlinksi Index (NI) is used as a sufficient condition to examine unstable closed-loop pairings [27].

$$
\begin{aligned}
& R G A(G(0))=G(0) \otimes\left(G(0)^{-1}\right)^{T} \\
& N I=\frac{\operatorname{det}[G(0)]}{\prod_{i=1}^{2} G(0)_{i j}}
\end{aligned}
$$

\subsection{Independent open loop Transfer Function $\left(T_{11}(s), T_{22}(s)\right)$.}

This TITO system $(2 \times 2)$ can be decompose into two independent loops (SISO system) using the inverted decoupler matrix $[5,28]$. 
The transfer function matrix of inverted decoupler is,

$$
\begin{aligned}
& D(s)=\left[\begin{array}{ll}
D_{11}(s) & D_{12}(s) \\
D_{21}(s) & D_{22}(s)
\end{array}\right] \\
&=\left[\begin{array}{cc}
1 & -\frac{G_{12}(s)}{G_{11}(s)} \\
-\frac{G_{21}(s)}{G_{22}(s)} & 1
\end{array}\right]
\end{aligned}
$$

So, the decomposed apparent systems $\mathrm{T}(\mathrm{s})$ are,

$$
\begin{aligned}
& \mathrm{T}(\mathrm{s})=\mathrm{G}(\mathrm{s}) \cdot \mathrm{D}(\mathrm{s})=\left[\begin{array}{cc}
\mathrm{T}_{11}(\mathrm{~s}) & 0 \\
0 & \mathrm{~T}_{22}(\mathrm{~s})
\end{array}\right] \\
& =\left[\begin{array}{cc}
\mathrm{T}_{11}(\mathrm{~s})^{*} & 0 \\
0 & \mathrm{~T}_{22}(\mathrm{~s})^{*}
\end{array}\right]
\end{aligned}
$$

The is $\mathrm{T}_{11}(\mathrm{~s})$ the Independent open loop transfer function between inputu1 and $\mathrm{y} 1$, with second loop is closed. also, $\mathrm{T}_{22}(\mathrm{~s})$ is the Independent open loop transfer function between input $\mathrm{u} 2$ and $\mathrm{y} 2$, with first loop 1 is closed.

The higher order independent system $\operatorname{diag}\left(\mathrm{T}_{11}(\mathrm{~s}), \mathrm{T}_{22}(\mathrm{~s})\right)$ is reduced into fractional order models $\left(\mathrm{T}_{11}(\mathrm{~s})^{*}, \mathrm{~T}_{22}(\mathrm{~s})^{*}\right)$ of type NIOPTD (non integer order plus time delay) Model

\subsection{Model Order Reduction}

Various techniques were suggested to reduce the diagonal elements of the independent system $\left(T_{11}(s), T_{22}(s)\right)$ to integer order transfer functions $[21,29,30]$. In this paper a fractional order transfer functions of type "One Non-Integer Orders Plus Time Delay (NIOPTD-I) " model $[12,31]$ is employed as the equivalent transfer function of Independent open loop Transfer Functions $\left(T_{11}(s), T_{22}(s)\right)$.

The general form of the NIOPTD-I model is as follows:

$$
T(s)^{*}{ }_{i i}=\frac{K_{i i}}{T_{i i} s^{\beta_{i i}}+1} e^{-L_{i i} s} \text { here } ; 0<\beta_{i i}<2 \text { (14) }
$$

where:

$\mathrm{i}=1,2 ; \mathrm{K}_{\mathrm{ii}} \rightarrow$ process gain ; $\mathrm{L}_{\mathrm{ii}} \rightarrow$ delay time;

$\mathrm{T}_{\mathrm{ii}} \rightarrow$ are time constaant; $\beta_{\mathrm{ii}} \rightarrow$ the fractional system order.

The number of tuning parameters of each fractional order model $\left(T_{11}(s)^{*}, T_{22}(s)^{*}\right)$ is written in vector form as follows:

$x_{1}=\left[\begin{array}{llll}K_{1} & T_{1} & L_{1} & \beta_{1}\end{array}\right]$ for the first $\operatorname{model} T_{11}(s)^{*}$ $x_{2}=\left[\begin{array}{llll}K_{2} & T_{2} & L_{2} & \beta_{2}\end{array}\right]$ for the second model $T_{22}(s)^{*}$.
The conditions of these optimized parameters are given by.

$$
\left\{\begin{aligned}
K_{\min } & <K_{1,2}<K_{\max } \\
0 & <T_{1,2}<T_{\max } \\
0 & <L_{1,2}<L_{\max } \\
0 & <\beta_{1,2}<2
\end{aligned}\right.
$$

The model reduction method based on using particle swarm optimization (PSO) algorithm proposed by Chuong et al. [21, 31] is implemented in MATLAB's Optimization Toolbox to obtain out the values of reduced order model parameters in equation (14).

This method of reducing higher order Independent systems in fractional order templates (NIOPDT) by minimizing the $H_{2}$ norm of the original higher order Independent models $\left(y_{1,2}\right)$ and reduced fractional order models $\left(\hat{y}_{1,2}\right)$ using an unconstrained optimization. i.e.

$$
J_{2-\text { norm }}=\frac{1}{n} \sum_{i=1}^{n}\left\|y_{1,2}-\hat{y}_{1,2}\right\|^{2}
$$

Where:

$$
\begin{aligned}
y_{1}=T_{11}(s) ; y_{2} & =T_{22}(s) ; \hat{y}_{1}=T_{11}(s)^{*} ; \\
\hat{y}_{2} & =T_{22}(s)^{*}
\end{aligned}
$$

The proposed objective function for fractional models reduction is given by:

$$
\begin{gathered}
J_{\min }\left(K_{1}, T_{1}, L_{1}, \beta_{1}\right)=\frac{1}{n} \sum_{i=1}^{n}\left(y_{1}-\hat{y}_{1}\right)^{2} \\
\text { for the first model. } \\
J_{\min }\left(K_{2}, T_{2}, L_{2}, \beta_{2}\right)=\frac{1}{n} \sum_{i=1}^{n}\left(y_{2}-\hat{y}_{2}\right)^{2} \\
\text { for the second model. }
\end{gathered}
$$

as noted in the figure below

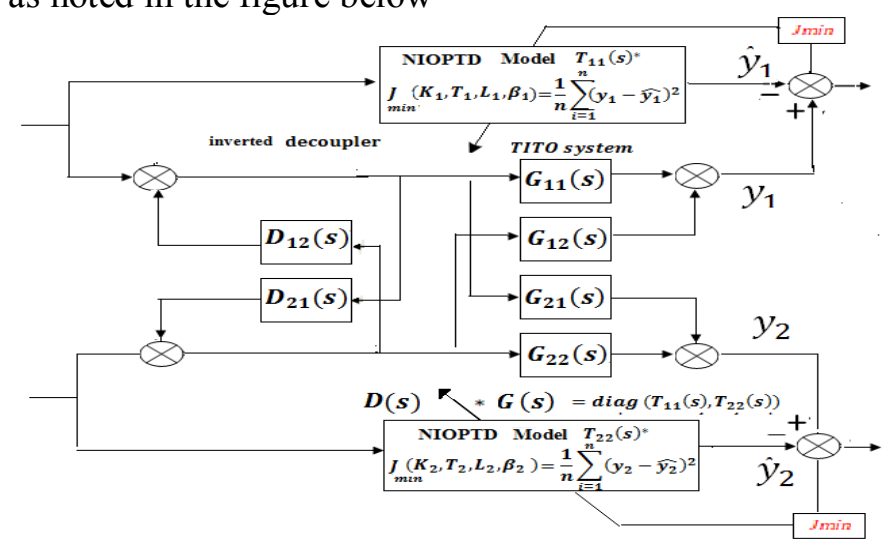

Fig.2. Structure of independent loops modeling into equivalent fractional order models (NIOPDT).

\section{Fractional IMC-PI-filter controller design}


This strategy is based on the principle that the fractional property of the designed controller is imposed by the fractional reference model $[13,25]$. It is an extension of classical PID tuning methods to the fractional PID tuning methods based on the equivalence between the classical feedback structures and the internal model control (IMC).

After designing the inverted decoupler, as shown in Fig. 3, The TITO systems become multi-loop systems. For each loop, a corresponding controller must be designed to meet the requirements of its closed loop fractional specifications.

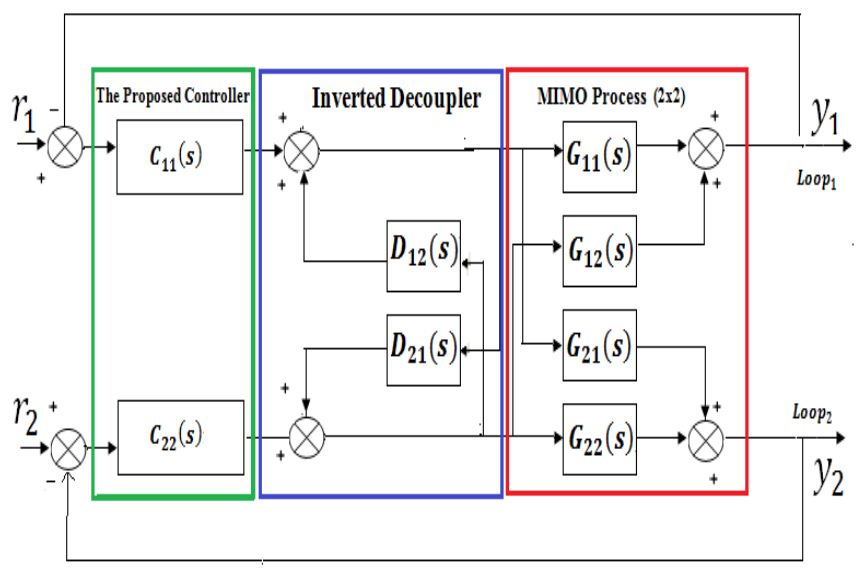

Fig. 3. Block diagram of the proposed multi-loop control structure for a (2x2) MIMO system with inverted decoupler.

In this work, the general structure of the fractional PID controller proposed for each loop is given by

$$
C(s)_{i i}=\underbrace{m(s)_{i i}}_{\text {FOF }} \underbrace{k p_{i i}\left(1+\frac{1}{T_{i i} \beta_{i i}}\right)}_{P^{\beta_{i i} \text { controller }}}
$$

As shown in equation $19, C(s)_{i i}$ is in the form of a non-integer order PI controller structure cascaded with a fractional order filter $(F O F) m(s)$.

Where: $k p_{i i}, \quad T_{i i}$ and $\beta_{i i}$ are proportional gain, integral time constant and integration order.

The Fractional IMC-PID filter controller design requires three steps $[13,25]$ :
Step 1: $T(s)_{i i}^{*}$ is divided as:

$$
T(s)_{i i}^{*}=T^{-}(s)_{i i}^{*} T^{+}(s)_{i i}^{*}
$$

Where $T^{+}(s)_{i i}^{*}$ Contains time delays and right half plane (RHP) zeros with $T^{+}(0)_{i i}^{*}=1$

Step 2: The IMC controller $C_{i m c}(s)_{i i}$ is designed by:

$$
C_{i m c}(s)_{i i}=\frac{1}{T^{-}(s)_{i i}^{*}} f(s)_{i i}
$$

Where:

$$
f(s)=\frac{1}{1+\tau_{c i i} \alpha_{i i}+1} ; 0<\alpha_{i i}<1
$$

$f(s)$ is the closed-loop Bode's ideal transfer function used as a reference model to obtain a fractional order controller, given by $[13,25]$. The two elements: the non integer $\boldsymbol{\alpha}_{i \boldsymbol{i}}$ and the time constant $\boldsymbol{\tau}_{\boldsymbol{c} i \boldsymbol{i}}$ are chosen to impose the crossover frequency $\omega c_{i i}$ and the phase margin $\boldsymbol{\phi}_{\boldsymbol{m i i}}$ of the each closed- loop

$$
\alpha_{i i}=\frac{\pi-\phi_{m i i}}{\pi / 2}-1 \text { and } \tau_{c i i}=\frac{1}{\omega c_{i i} \alpha_{i i}+1}
$$

Step 3: from the equivalence between the conventional feedback schema shown in Fig. 5 and the IMC schema represented in Fig. 4 we obtain:

$$
C(s)_{i i}=\frac{C_{i m c}(s)_{i i}}{1-C_{i m c}(s)_{i i} T(s)_{i i}^{*}}
$$

As previously shown in equation 19 , the controller $C(s)_{i i}$ structure can be put in two transfer functions: non-integer order PI controller structure cascaded with a fractional order filter

$$
C(s)_{i i}=\underbrace{m(s)_{i i}}_{F O F} \underbrace{k p_{i i}\left(1+\frac{1}{T_{i i} \beta_{i i}}\right)}_{P I^{\beta_{i i}} \text { controller }}
$$




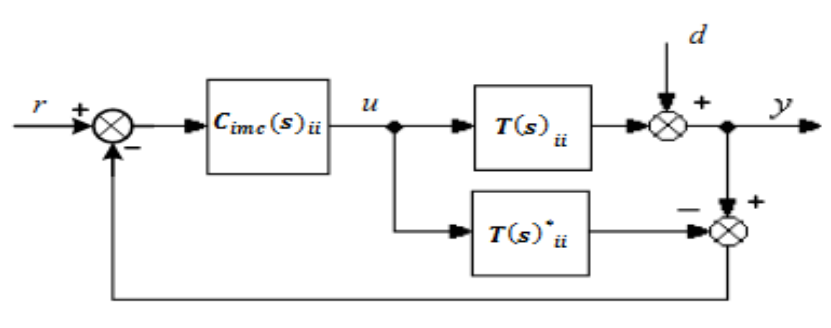

Fig. 4. Internal model control (IMC) structure.

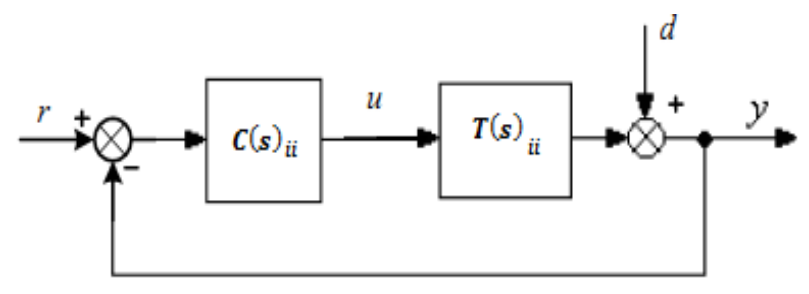

Fig. 5. Conventional feedback structure.

\subsection{Design procedure details}

For example in this work, we consider a non integer order plus time delay (NIOPTD) model expressed in equation 14.

$$
T(s)^{*}{ }_{i i}=\frac{K_{i i}}{T_{i i} s^{\beta_{i i}}+1} e^{-L_{i i} s}
$$

To deal with the delay term, it is usual to use a first order Taylor expansion of the $\boldsymbol{e}^{-L_{i i}}$ term is

$$
\boldsymbol{e}^{-L_{i i} S}=\mathbf{1}-L_{i i} S
$$

Equation 14 becomes as follows

$$
T(s)^{*}{ }_{i i}=\frac{K_{i i}\left(\mathbf{1}-L_{i i} s\right)}{T_{i i} s^{\beta_{i i}}+1}
$$

The IMC controller according to equation (21) is

$$
C_{i m c}(s)_{i i}=\frac{1+T_{i i} s^{\beta_{i i}}}{K_{i i}\left(1+\boldsymbol{\tau}_{c i i} \boldsymbol{s}^{\alpha_{i i}+\mathbf{1}}\right)}
$$

Hence the corresponding feedback controller is obtained by:

$$
\begin{aligned}
& C(s)_{i i}=\frac{1+T_{i i} s^{\beta_{i i}}}{K_{i i}\left(\tau_{c i i} s^{\alpha_{i i}+1}+L_{i i} s\right)} \\
& =\frac{1+T_{i i} s^{\beta_{i i}}}{K_{i i} L_{i i}\left(1+\left(\tau_{c i i} / L_{i i}\right) s^{\left.\alpha_{i i}\right) \mathrm{s}}\right.}
\end{aligned}
$$

Which can be rewritten in the form of equation (31),

$$
C(s)_{i i} \underbrace{\frac{s^{\beta i i-1}}{1+\left(\tau_{\text {cii }} / L_{i i}\right) s^{\alpha i i}}}_{\text {fractional filter }_{i i}} \underbrace{\frac{1}{K_{i i} L_{i i}}\left(\frac{1+T_{i i} s^{\beta i i}}{s^{\beta i i}}\right)}_{\text {fractional PI }^{\beta i i}}
$$

\section{Simulation Results:}

The transfer function matrix of Wood Berry (WB) $2 \times 2$ binary distillation process [32] is considered for simulation study and expressed by

$$
G_{1}(s)=\left[\begin{array}{ll}
\frac{12.8}{16.7 s+1} e^{-s} & \frac{-18.9}{21 s+1} e^{-3 s} \\
\frac{6.6}{10.9 s+1} e^{-7 s} & \frac{-19.4}{14.4 s+1} e^{-3 s}
\end{array}\right]
$$

The matrix of RGA elements and NI value are:

$$
R G A(G(0))=\left[\begin{array}{cc}
2.0094 & -1.0094 \\
-1.0094 & 2.0094
\end{array}\right], \mathrm{NI}=0.4977
$$

We observe from the analysis of the RGA matrix and the value of NI that the best pairing is ( $u 1-$ $y 1)$ and $(u 2-y 2)$.

The inverted decoupler $D(s)$ is design using equation 12.

$$
D_{1}(s)=\left[\begin{array}{cc}
1 & \frac{1.477(16.7 s+1)}{21 s+1} e^{-2 s} \\
\frac{0.34(14.4 s+1)}{10.9 s+1} e^{-4 s} & 1
\end{array}\right]
$$

The decoupled processes $\left(T_{11}(s), T_{22}(s)\right)$ are obtained using equation 13 .

$$
\begin{gathered}
T_{11}(s)=\frac{1}{1-\frac{0.5017(14.4 s+1)(16.7 s+1)}{(10.9 s+1)(21 s+1)}}\left(\frac{12.8}{(16.7 s+1)} e^{-1 s}\right. \\
\left.-\frac{6.43(14.4 s+1)}{(21 s+1)(10.9 s+1)} e^{-7 s}\right) \\
T_{22}(s)=\frac{1}{1-\frac{0.5017(14.4 s+1)(16.7 s+1)}{(10.9 s+1)(21 s+1)}}\left(-\frac{19.4}{(14.4 s+1)} e^{-3 s}\right. \\
\left.+\frac{9.7453(16.7 s+1)}{(21 s+1)(10.9 s+1)} e^{-9 s}\right)
\end{gathered}
$$

Then, using the methodology proposed in Section 3, the results of the fractional order models are obtained by the following equations:

Where

$$
\begin{aligned}
G(s) \cdot D(s)= & {\left[\begin{array}{cc}
T_{11}(s) & 0 \\
0 & T_{22}(s)
\end{array}\right] } \\
& =\left[\begin{array}{cc}
T_{11}(s)^{*} & 0 \\
0 & T_{22}(s)^{*}
\end{array}\right]
\end{aligned}
$$

and

$$
T_{11}^{*}(s)=\frac{13.145}{15.9588 s^{0.98004}+1} e^{-1.2107 s}
$$

$$
T_{22}{ }^{*}(s)=\frac{-19.7716}{14.1168 s^{0.98897}+1} e^{-3.1034 s}
$$

To evaluate how closely the reduced NIOPDT model approximates the each decoupled subsystem, step responses are drawn in Fig. 6. 
From Fig. 6 we notice that the NIOPTD-II models are very close to the original subsystems. This indicates that the proposed method for approximating these systems gave a high efficiency and demonstrated its effectiveness.
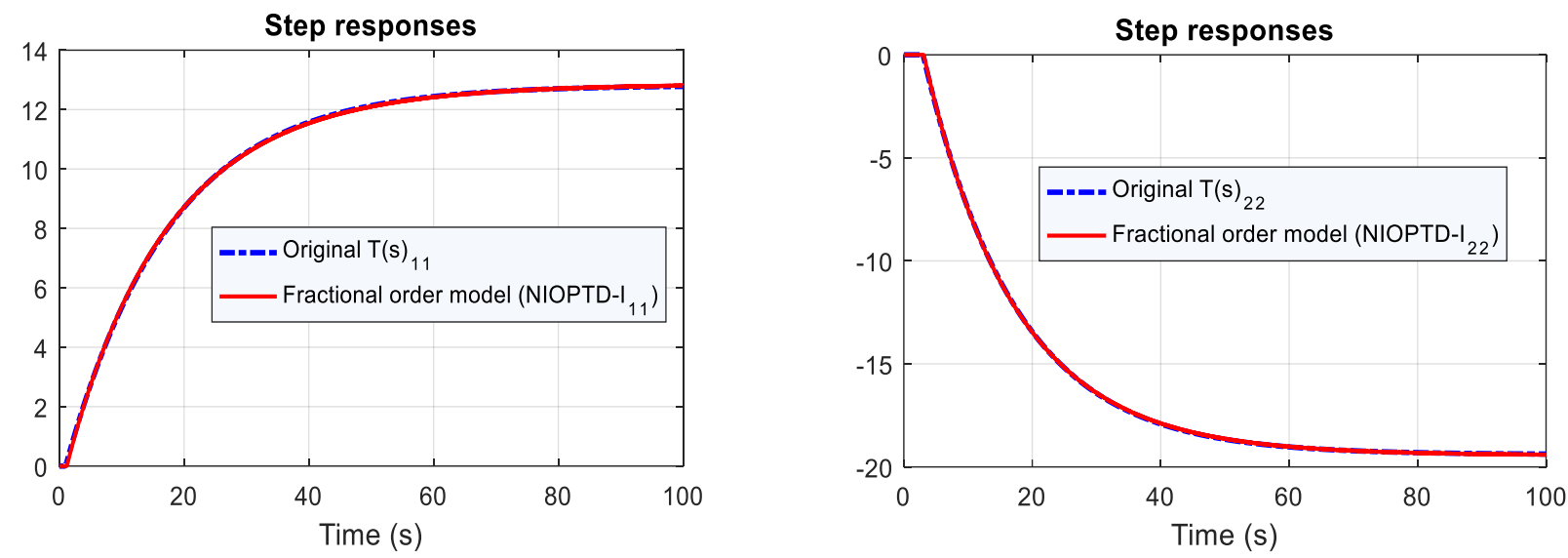

Fig. 6. Step response of decoupled subsystems $\left(\mathrm{T}_{11}(\mathrm{~s}), \mathrm{T}_{22}(\mathrm{~s})\right)$ and their equivalent approximations $\left(\mathrm{T}_{11}(\mathrm{~s})^{*}, \mathrm{~T}_{22}(\mathrm{~s})^{*}\right)$.

For this simulation example, the specifications for the desired closed loop model (see Eq. (19)) are selected in terms of gain crossover frequencies, $\omega c_{11}=\omega c_{22}=0.4 \quad \mathrm{rad} / \mathrm{s}$ and phase margins, $\boldsymbol{\phi}_{\boldsymbol{m 1 1}}=\boldsymbol{\phi}_{\boldsymbol{m 1 1}}=\mathbf{8 1}{ }^{\circ}$ of loop 1 and loop 2 by Eq. (19). Where we found The values of time constants are: $\boldsymbol{\tau}_{\boldsymbol{c 1 1}}=\boldsymbol{\tau}_{\boldsymbol{c 2 2}}=\mathbf{2 . 7 3 9 9}$ The values of the fractional order $\boldsymbol{\alpha}_{\mathbf{1 1}}=\boldsymbol{\alpha}_{\mathbf{2 2}}$ are $\mathbf{0 . 1}$ These values are chosen to meet the desired specifications of the closed loop model in the frequency domain. The fractional IMC-PI-filter controller obtained with this method proposed is presented in Table 1 .
In this paper, the proposed method is compared to the latest advanced work and new results obtained by the researchers in the field of multivariable systems control such as Techniques proposed by Chuong et al. the simplified decoupling Smith predictor structure by approximated fractional order models (F-SDSP) [20], the SDSP by approximated integer order models [21] and multi-loop PID controller based on the root locus Technique with inverted decoupling [5].

The controllers that are designed by these Techniques in $[20,21,5]$ for the same simulation example are listed in Table 1.

Table 1: The Resulting Multi-loop Controllers with Different Tuning Methods.

\begin{tabular}{|c|c|}
\hline Tuning Method & The Resulting Controllers \\
\hline $\begin{array}{c}\text { Proposed } \\
\text { Fractional IMC-PI-filter } \\
\text { controller design }\end{array}$ & $C(s)_{11}=\frac{s^{-0.01996}}{1+2.263 s^{0.10}} 1.0027\left(1+\frac{1}{15.9588 s^{0.98004}}\right)$ \\
\hline $\begin{array}{c}\text { Fractional-SDSP } \\
\text { Chuong et al. 2019 [20]. }\end{array}$ & $C(s)_{22}=\frac{s^{-0.01103}}{1+0.88287 s^{0.10}}(-0.23)\left(1+\frac{1}{14.1168 s^{0.98897}}\right)$ \\
\hline $\begin{array}{c}\text { Classical-SDSP } \\
\text { Chuong et al. 2019 [21]. }\end{array}$ & $C(s)_{11}=0.2882 \frac{1}{s^{0.1286}}\left(1+\frac{1}{7.1079 s^{0.8714}}\right)$ \\
\hline $\begin{array}{c}\text { Classical-PID } \\
\text { Chananchai et al. 2018 [5]. }\end{array}$ & $C(s)_{22}=-0.1212 \frac{1}{s^{0.1538}}\left(1+\frac{1}{5.2645 s^{0.8462}}+0.6385 s^{0.9418}\right) \frac{1}{1.1 s+1}$ \\
\hline & $C(s)_{22}=-0.330\left(1+\frac{1}{14.4815}+0.1428 s\right) \frac{1}{8.274 s+1}$ \\
\hline
\end{tabular}


The result of closed-loop system step response of the both loops (loop1 and loop2) are shown in Figs 7 and 8 , respectively, with a unit step changes in the setpoint are sequentially, for loop- 1 at $\mathrm{t}=0 \mathrm{sec}$ and loop-2 at $\mathrm{t}=100 \mathrm{sec}$.

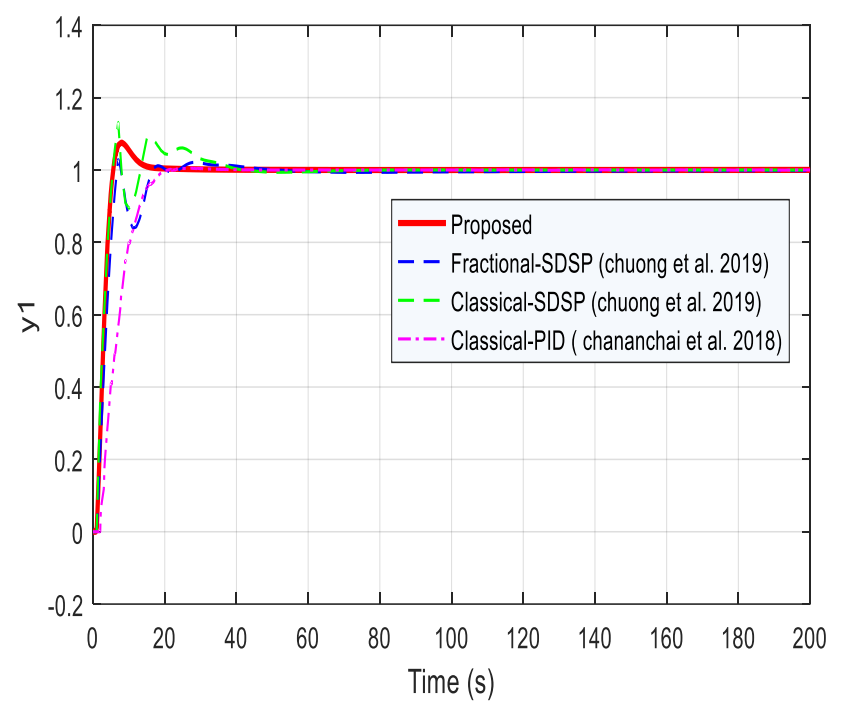

Fig. 7. Responses of WB column: $y_{1}$ closed-loop response to unit step in $r 1$-at $t=0$ and $r 2$-at $t=100$.

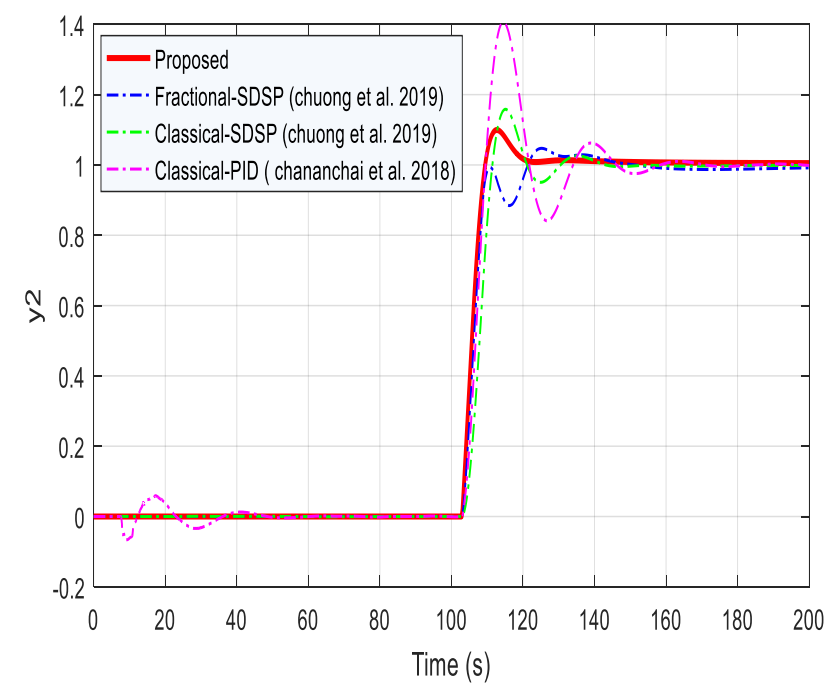

Fig. 8. Responses of WB column: $y_{2}$ closed-loop response to unit step in $r 1$-at $t=0$ and $r 2$-at $t=100$.

We enclose our work by adding a control signal for the two loops as shown in Figs 9 and 10, respectively.

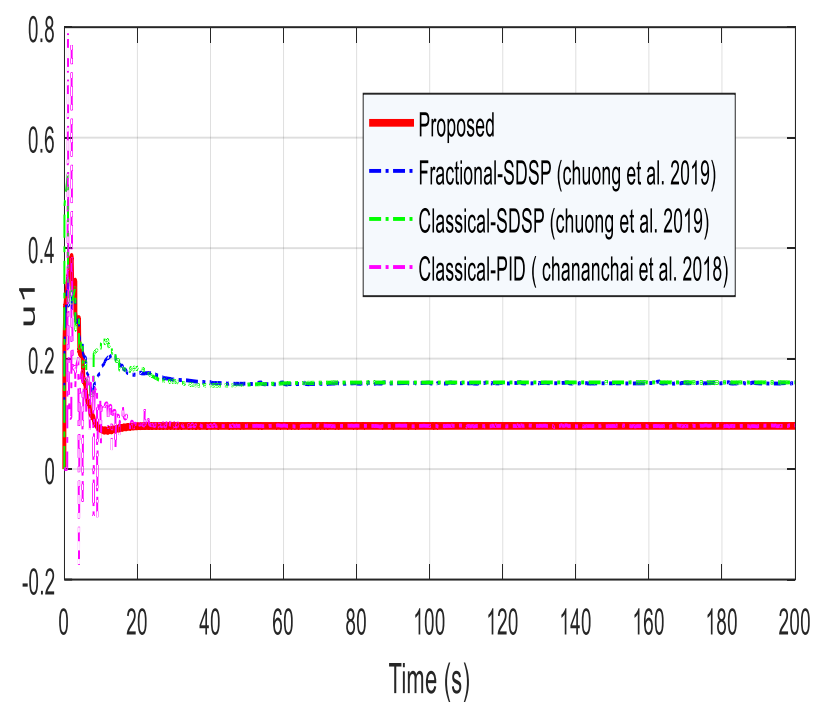

Fig. 9. The control signal response in loop 1.

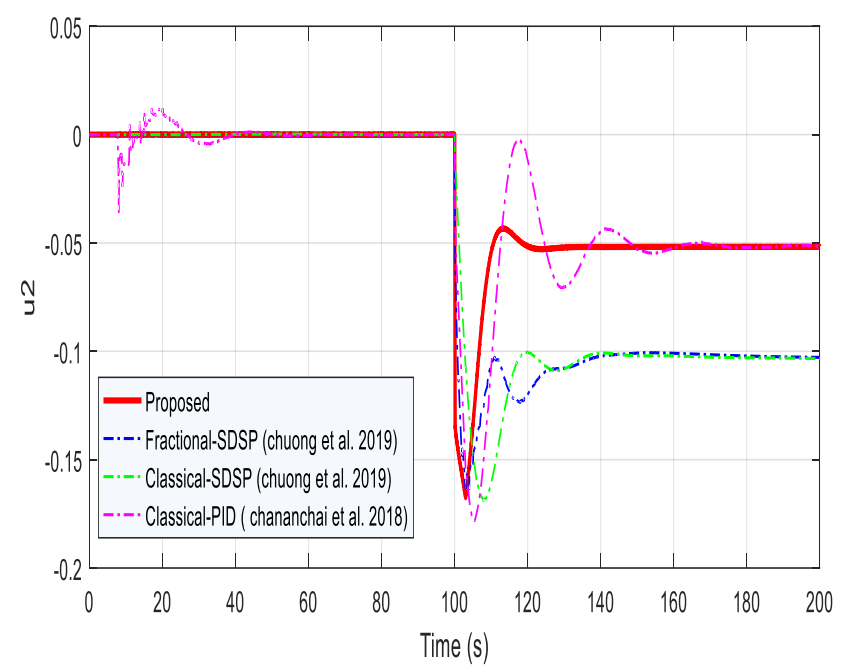

Fig. 10. The control signal response in loop 2.

The performance index such as integral absolute error (IAE) and time domain specifications as settling time (sec) and peak overshoot (\%) of the four methods are summarized in Table2. 
Table 2: Results of the performance analysis and comparison.

\begin{tabular}{|c|c|c|c|c|c|}
\hline \multirow{2}{*}{ Tuning Method } & \multicolumn{2}{|c|}{ Settling time $(\mathrm{sec})$} & \multicolumn{2}{|c|}{ Overshoot \% } & IAE \\
\cline { 2 - 6 } & $\begin{array}{c}\text { Loop }_{1} \\
(y 1-r 1)\end{array}$ & $\begin{array}{c}\text { Loop } \\
y 2-r 2)\end{array}$ & $\begin{array}{c}\text { Loop }_{1} \\
(y 1-r 1)\end{array}$ & $\begin{array}{c}\text { Loop }_{2} \\
(y 2-r 2)\end{array}$ & Loop $_{1}+$ Loop $_{2}$ \\
\hline Proposed Controller & 9.98 & 16.77 & 7.6 & 10.01 & 9.053 \\
\hline $\begin{array}{c}\text { Fractional-SDSP } \\
\text { (Chuong et al. 2019) }\end{array}$ & 14.86 & 19.99 & 3.11 & 5.07 & 10.963 \\
\hline $\begin{array}{c}\text { Classical-SDSP } \\
\text { (Chuong et al. 2019) }\end{array}$ & 26.14 & 25.32 & 13.09 & 15.89 & \\
\hline $\begin{array}{c}\text { Classical-PID } \\
\text { (Chananchai et al. 2018) }\end{array}$ & 14.92 & 40.82 & 0.52 & 41.03 & 12.08 \\
\hline
\end{tabular}

To demonstrate the efficiency of the proposed design method, simulation responses are given (see in Figs 9 and 10) and Table 3, and we note from them that the multi-loop fractional IMC-PID-filter controller proposed achieves a good performance in term of percent overshoot (\%) and settling (sec) time compared with the performance of multi-loop controller design (F-SDSP and SDSP) introduced by Chuong et al. [20, 21] and decentralized controller design presented by Chananchai et al. [5].

In addition to evaluating the closed-loop performance index, the integral absolute error (IAE) criterion was considered, and it is observed that performance with the proposed controller is giving good and superior results when compared to other multi-loop controllers.

Also from Figs. 9 and 10, it is clear that the proposed fractional controller generates and gives a very smooth control procedure among those methods and this is a confirmation of the results obtained.

As a contribution from us in this paper and from the results achieved by our proposed method by comparing it with the latest works reached by researchers, we confirmed the effectiveness and success of the proposed method despite the difficulty of implementation in MIMO systems. We can also say that the use of the multi-loop fractional IMC-PID-filter controller with an inverted decoupler for $2 \times 2$ MIMO systems using the proposed technique provides good performance and robustness. This is due to the use of the closed loop Bode's ideal transfer function as a reference model.

\section{Prospects for my future Research:}

In my future work, I will combine this methodology with Computational Intelligence (Fuzzy Logic, Neural Networks, Genetic Algorithms). I will also extend this methodology to include discrete Systems and 2-D Systems.

\section{Conclusion:}

In this paper, the $2 \times 2$ MIMO systems was transformed into two independent SISO system by introducing an inverted decoupler, and reduces each SISO system to the equivalent NIOPTD model. .The multi-loop fractional IMC-PID-filter controllers is designed based on the IMC paradigm for NIOPTD models in an analytical method. Thus the proposed controller parameters are determined to satisfy gain crossover frequencies and phase margins specifications of the Bode's ideal closed loop transfer function as the reference model for each loop. Simulation results show clearly that the time domain specifications and the performance index (settling time (sec), peak overshoot (\%) settling time, and IAE) given by of the controlled system responses with the proposed controller gives a good performance and acceptable in comparison with the multi-loop fractional PI/PID controllers based on FSDSP and C-SDSP structure as well as conventional PID controllers using root locus method.

\section{Reference:}

[1] R. Hanuma Naik, D. V. Ashok Kumar and K. S. R. Anjaneyulu. "A Comparative Study of Decoupler Design Techniques for TITO Control Processes." Emerging Trends in Electrical, Communications and Information Technologies, Lecture Notes in Electrical Engineering, vol 394.Springer,Singapore. (2017). pp 293-301

[2] V. D. Hajare, B. M. Patre, A. A. Khandekar, and G. M. Malwatkar, "Decentralized PID controller design for TITO processes with experimental validation, " International Journal 
of Dynamics and Control, doi:10.1007/s40435016-0252-z, June 2016.

[3] V. D. Hajare, B. M. Patre, "Decentralized PID controller for TITO systems using characteristic ratio assignment with an experimental application". ISA Transactions (2015), http: //dx.doi.org/10.1016/j.isatra.2015.10.0 08i

[4] R. Hanuma Naik, D. V. Ashok Kumar, P. Sujatha "Independent controller design for MIMO processes based on extended simplified decoupler and equivalent transfer function ".Ain Shams Engineering Journal, 2019 - Elsevier

[5] Ch. Wutthithanyawat, and S. Wangnipparnto. "Design of decentralized PID controller with the root locus method based on inverted decoupling for a TITO system." Journal of Thai Interdisciplinary Research 13.2 (2018).

[6] Q.Jin, Q. Wang, and L. Liu, "Design of decentralized proportional-integral-derivative controller based on decoupler matrix for twoinput/two-output process with active disturbance rejection ". Advances in Mechanical Engineering 2016, Vol. 8(6) 1-18.

[7] C.Rajapandiyan, and M.Chidambaram, "Controller design for MIMO process based on simple decoupled equivalent transfer function and simplified decoupler", Industrial \& Engineering Chemistry Research, Vol.51, pp.12398-12410, 2012.

[8] B. Boudjehem,and D. Boudjehem " Fractional PID controller design based on minimizing performance indices. IFAC-PapersOnLine 49 (9):164-168. (2016).

[9] J. Bhookya1, R. K. Jatoth "Optimal FOPID/PID controller parameters tuning for the AVR system based on sine-cosine-algorithm". Evolutionary Intelligence. vol. 12, pp.725733(2019).springer.

[10] D. Boudjehem, M. Sedraoui, and B. Boudjehem, A fractional model for robust fractional order smith predictor. Nonlinear Dynamics , 73( 3), 1557-1563, (2013).

[11] C. Thammarat, D. Puangdownreong, Design of Fractional Order PID Controller for Induction Motor Speed Control System by Cuckoo Search International Journal of Circuits, Systems and Signal Processing, pp. 92-96, Volume 13, 2019

[12] D. Li, L. Liu, Q. Jin, K. Hirasawa, "Maximum Sensitivity Based Fractional IMC-PID Controller Design for Non-integer Order System with Time Delay", Journal of Process Control, 31 (4), 17-29(2015).
[13] M. Bettayeb, and R. Mansouri, "Fractional IMC-PID-filter controllers design for non integer order systems". J. Process Control 24(4), 261-271 (2014)

[14] S. Laifa, and B. Boudjehem, "A New Design Method for Fractional Order Proportional Integral (FO-PI) Controller of 3x3 Multivariable Systems", Algerian Journal of Signals and Systems, Vol. 5, Issue 1, March 2020. pp: 7378.

[15] B. Boudjehem and S. Laifa, " Optimal Tuning Method of decentralised Fractional PI Controller for TITO Process using Diffusive ApproachISBN: 978-9938-9937-1-41", Proceedings of the 3th International Conference on Recent Advances in Electrical Systems, ISBN: 978-9938-9937-1-41 pages: 113-116, Tunisia, December 2018.

[16] S. Laifa and B. Boudjehem, " Analytical Synthesis of Decentralized Fractional Order Controllers for MIMO Processes Based on Fractional Reference Model", Proceedings of the 4th International Conference on Recent Advances in Electrical Systems, ISBN: 9789938-9937-2-1; pages: 24-30, Tunisia, December 2019.

[17] S.K. Lakshmanaprabu, U. Sabura Banu, and P.R. Hemavathy. "Fractional order IMC based PID controller design using Novel Bat optimization algorithm for TITO Process".Energy Procedia,vol.117,pp.11251133. 2017.

[18] T. Chekari, R. Mansouri, and M. Bettayeb, "IMC-PID Fractional Order Filter Multiloop Controller Design for Multivariable Systems Based on Two Degrees-of-Freedom Control Scheme, " Int. J. Control, Autom. Syst., 16(2), pp. 689-701, 2018.

[19] D. Li, X. He, T. Song, and Q. Jin, "Fractional Order IMC Controller Design for Two-inputtwo-output Fractional Order System". Int. J. Control Autom. Syst. 2019, 17, 936-947.

[20] V.L. Chuong, T.N.L. Vu, N.T.N. Truong, and J.H. Jung, " A Novel Design of Fractional PI/PID Controllers for Two-Input-Two-Output Processes". Appl. Sci. 2019, 9(23), 5262; doi:10.3390/app9235262.

[21] V.L. Chuong, T.N.L. Vu, N.T.N. Truong, and J.H. Jung, "An Analytical Design of Simplified Decoupling Smith Predictors for Multivariable Processes". Appl. Sci. 2019, 9, 2487.

[22] C.A. Monje, Y. Chen, B.M. Vinagre, D. Xue, and V. Feliu-Batlle, "Fractional-Order Systems 
and Controls: Fundamentals and Applications". Springer. ISBN 9781849963350. (2010).

[23] H.W. Bode, Network Analysis and Feedback Amplifier Design, Van Nostrand, New York, 1945.

[24] R.S. Barbosa, J.A.T. Machado, and I.M. Ferreira, Tuning of PID controllers based on Bode's ideal transfer function, Nonlinear Dynamics 38 (2004) 305-321.

[25] M. Bettayeb, and R. Mansouri, "IMC-PIDfractional-order-ilter controllers design for integer order systems, " ISA Trans., Vol. 53, No. 5, pp. 1620-1628 (2014).

[26] E. Yumuk, M. Güzelkaya and 'I. Eksin, Analytical fractional PID controller design based on Bode's ideal transfer function plus time delay. ISA Transactions (2019),https://doi.org/10.1016/j.isatra.2019.01.0 34

[27] M-S. Chiu, and Y. Arkun, "A new result on Relative Gain Array, Niederlinski Index and decentralized stability condition: $2 \times 2$ plant cases", Automatica, Volume 27, Issue 2, March 1991, Pages 419-421.

[28] P. Chen, and W. Zhang, "Improvement on an inverted decoupling technique for a class of stable linear multivariable processes". ISA Trans. 2007; 46: 199-210.

[29] D.K. Maghade, and B.M. Patre, "Decentralized PI/PID controllers based on gain and phase margin specifications for TITO processes". ISA Trans 2012;51(4):550-8.

[30] M. Hofreiter and A. Hornychova, "The Use of Relay Shifting Method of Process Identification for Auto Tuning of PID Controller", International Journal of Circuits, Systems and Signal Processing, pp. 721-726, Volume 13, 2019

[31] S. Das, S. Saha, S. Das, and A Gupta, "On the selection of tuning methodology of FOPID controllers for the control of higher order processes". ISA Transactions. 2011;50(3):37688.

[32] R.K.Wood, and M.W. Berry, "Terminal composition control of binary distillation column". Chem. Eng. Sci. 1973, 28, 1707-1717.

\section{Creative Commons Attribution License 4.0 (Attribution 4.0 International, CC BY 4.0)}

This article is published under the terms of the Creative Commons Attribution License 4.0

https://creativecommons.org/licenses/by/4.0/deed.en_US 